\title{
Spatial Configuration of Coastal Tourist Settlements: Design Principles and Paradigmes
}

\author{
S. P. Pieri, A. Zargli, I. Tzouvadakis \\ Department of Civil Engineering \\ National Technical University of Athens, Greece
}

\begin{abstract}
The following research is an effort to develop design principles for coastal tourist settlements depending on the relationship between the shape of a site, to its location and to its orientation. For that purpose, we use a figurative tourist complex as a comparison tool, covering typical cases of tourist development in coastal zones. The analysis is based on the principles of passive bioclimatic design using computer simulation processes. More specifically, by combining the ACAD software with the A-Lisp programming software, we produced the software called ROUTINA BIOCLIMA which dismantles and analyzes the digitized road network. The study, by considering the orientation of the streets as the primary factor, comes up with estimations about the quality of the built environment and the daylight distribution, in addition to conclusions about design decisions for the configuration of the touristic settlement in relation to the geomorphology of the soil, the duration and the intensity of local winds, the humidity and the amount of rainfall in the area in which it belongs to, as well as its relation to the waterfront.
\end{abstract}

Key-words - Coastal tourist settlements, configuration, road network, design decisions, ROUTINA BIOCLIMA

\section{INTRODUCTION}

In the case of coastal areas large bodies of water affect the microclimate of the region and should be taken into account in the design of seaside tourist settlements. This research focuses primarily on the structure of the auxiliary vehicular and pedestrian road network and the impact it can have on the conditions of visual and thermal comfort inside the buildings and the microclimate of a particular tourist area. By successfully planning and efficiently orienting the building units on site in accordance to the principles of sustainability, one can optimize the natural daylight conditions inside the buildings, and thus increase the efficiency of the passive

heating and cooling systems used in each unit. In the case of a tourist complex very often, the need for achieving thermal comfort through the correct orientation of building units does not necessarily always comply with the requirement for good sight lines towards the view, it is necessary therefore to find solutions through design. The second part of the site focuses on a series of additional parameters such as the geometry of the layout in relation to the ratio of the width of the streets to the height of the tourist units, the density and choice of the planting elements, the size of the openings depending on the orientation of each façade and its relation to the sea front etc. to form a second set of principles that could enhance the sustainable character of tourist settlements.

\section{Climatological Data As A Key Design Principle}

The sea affects the microclimate of Coastal areas. These areas are in general characterized by the following phenomena, which should always be taken into account before designing a coastal tourist settlement:

a. High levels of Humidity. Air moves from the region of higher density to a region of lower density and this causes the sea air to be blown towards the adjoining coastal regions thus bringing in a lot of water vapor and thereby increasing humidity.

b. Higher Temperatures during winter and fall. Bodies of water have a damping effect on the swing in temperatures of coastal areas. That is, while inland regions can quickly decrease in temperature from the fall to winter seasons, shoreline towns are kept warmer by the water's effect on the air. This is due to water's high heat capacity compared to both air and land. Therefore, shoreline towns will experience warmer winters and cooler summers than inland communities.

c. Wind dynamics. Shoreline communities experience an interesting dynamic between the air over water and the air over land. Air tends to move from cooler areas toward warmer areas, and the sun often dictates whether the land or sea is cooler. During the daytime, the air onshore is warmer than the air over the sea, so the wind blows from the sea to the land. At night, the opposite occurs since the air over the sea is warmer.

d. Oceanic Currents. The direction of oceanic currents greatly affects the climate of coastal towns, i.e. the Gulf Stream current, which runs rapidly up the eastern seaboard from the Caribbean, bringing relatively warm water up into cooler climates. This current runs into the Gulf of Mexico, where it has a chance to increase in temperature before it runs back down around Florida then turns northward. On the West Coast of the United States, the current runs from the Gulf of Alaska down along the Pacific Coast, bringing colder water with it.

e. High rate of salinity. The high salinity of the sea water increases the level of corrosion of construction materials and their need of maintenance and their life cycle in the buildings. To sum up, Coastal areas have a very distinctive microclimate which is associated with the large bodies of water and the geographical ongitude and latitude of the region. 


\section{ORIENTATION AS A DESIGN PRINCIPLE FOR THE} CONFIGURATION OF COASTAL TOURIST SETTLEMENTS

The first part of the research focuses on considering different typical figurative tourist complex configurations and site orientations by taking into account the previously mentioned climatological characteristics of coastal areas and aims to draw conclusions and to develop design principles for the design of tourist settlements depending on the relationship of the shape of a site to its location, its orientation and its relation to the waterfront. For the purpose of this study, the simulation software Routina Bioclima was implemented.

The software Routina Bioclima is an LSP file that runs on AutoCAD and has the ability to classify roads according to whether they show favorable orientation or not. More specifically, for each of the tourist complexes under consideration, it creates an AutoCAD file with its road network divided in eight equal sections of 22.5 degrees. In this way, it is possible to calculate the number and length of roads in each orientation. It is obvious that only the streets listed in the $1^{\text {rst }}$ and $8^{\text {th }}$ section have the desired angle with respect to solar radiation. Unlike, the streets in the $4^{\mathrm{rth}}$ and $5^{\text {th }}$ section which are considered as the most unfavorable, while the rest of the orientations are neutral.

\section{A. Rectilinear Layout in Lowland Areas, North-South central Axis}

Firstly, the study examines and evaluates tourist complexes, which are located in lowland areas, facing the waterfront either to the east or west in a strict linear arrangement.

According to Fig.1, the results of processing the network of roads of the tourist complex show that the number of roads that are favorably oriented reaches $83.33 \%$ of the total and their corresponding length is $23.82 \%$, as opposed to the number of unfavorably oriented, which amounts to $16.67 \%$ and $76.18 \%$ respectively.

It should be noted that the percentages of the unfavorably oriented roads are substantially higher than rates of the favorably oriented. This particularity lies in the fact that the main circulation axis that runs through the complex coincides with the north-south axis, and therefore the main "built front" is oriented east and west (unfavorable orientation). The side elevations of the buildings which are facing the secondary roads and are vertical to the central circulation axis have a favorable orientation. The results are analytically presented in table I.

TABLE I. RECTILINEAR LAYOUT ON AN EAST-WEST ORIENTATION

\begin{tabular}{|l|l|l|}
\hline & Length & Number \\
\hline Favorable Orientation & $23,82 \%$ & $83,33 \%$ \\
\hline Unfavorable lorientation & $76,18 \%$ & $16,67 \%$ \\
\hline
\end{tabular}

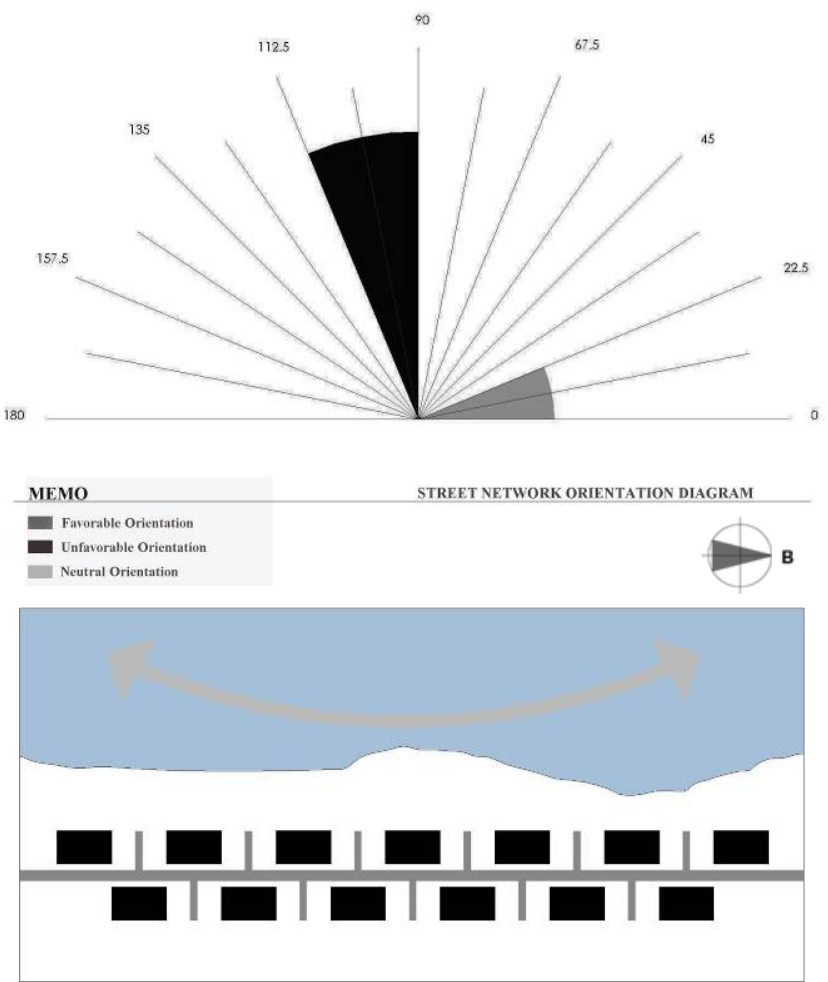

Figure 1. Street Network orientation diagram, as result of Routina Bioclima software, Master plan of settlement

To conclude, we could say that the development of a tourist complex on either side of a central circulation axis in cases where this central axis coincides with the direction North South does not give the desired outcome and results in buildings predominantly facing East - West.

\section{B. Radial Layout in Lowland Area, North-South central Axis}

Secondly, the study examines and evaluates tourist complexes which are located in lowland areas, facing the waterfront either to the east or west and are designed in a radial arrangement in relation to the adjacent coastline.

According to Fig.2, the results of the study show that the number of roads that are favorably oriented reaches $37,50 \%$ of the total and their corresponding length $35,92 \%$,in contrast to the number of the unfavorably oriented, which accounts to $62,50 \%$ and $64,08 \%$ respectively. The results are analytically presented in table II.

TABLE II.

RADIAL LAYOUT ON AN EAST-WEST ORIENTATION

\begin{tabular}{|l|l|c|}
\hline & Length & Number \\
\hline Favorable Orientation & $35,92 \%$ & $37,50 \%$ \\
\hline Unfavorable \orientation & $64,08 \%$ & $62,50 \%$ \\
\hline
\end{tabular}



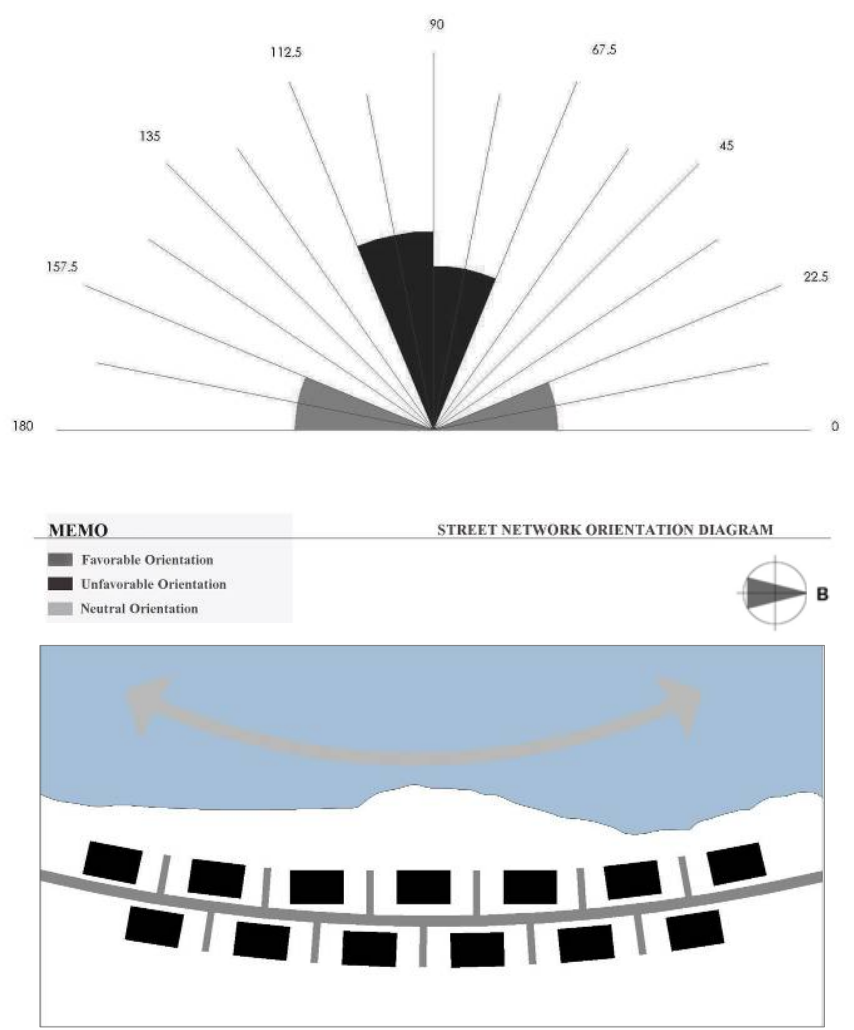

Figure 2. Street Network orientation diagram, as result of Routina Bioclima software, Master plan of settlement

From the previously mentioned results, it is obvious that the percentages of the negatively oriented roads are significantly reduced compared to the favorably oriented. This reduction is due to the curvature of the central circulation axis that runs through the complex and in this case follows the coastline. The curve allows the units to deviate from the axis of east - west and approach the 30th variation from the south orientation (a satisfactorily favorable orientation according to the program Routina Bioclima). Consequently, the slight deviation of the main road from the direction north - south leads to a significant reduction in the unfavorably orientated roads and buildings.

\section{Rectilinear Layout in Lowland Areas, East-West Central Axis}

This part of the study examines and evaluates tourist complexes which are located in lowland areas, facing the waterfront either to the north or south and are designed in a linear arrangement irrespectively of the adjacent coastline.

According to the results of processing the network of roads of the tourist complex, the number of roads that are favorably oriented reaches $8.33 \%$ of the total and their corresponding length is $59.24 \%$, as opposed to the unfavorably oriented which amounts to $91.67 \%$ and $40.76 \%$ respectively (see.Fig.3).

The results of processing the roads through the program Routina Bioclima are analytically presented in Table III and the network orientation diagram of the master plan.
TABLE III. RECTILINEAR LAYOUT ON A NORTH-SOUTH ORIENTATION

\begin{tabular}{|l|c|c|}
\hline & Length & Number \\
\hline Favorable Orientation & $59,24 \%$ & $8.33 \%$ \\
\hline Unfavorable lorientation & $40,76 \%$ & $91,67 \%$ \\
\hline & & \\
\hline
\end{tabular}

Figure 3. Street Network orientation diagram, as result of Routina Bioclima software, Master plan of settlement

It is observed, that the percentage of the favorably oriented roads exceeds the rates of the adversely oriented. The increase in favorable orientation is due to the fact that the central axis that runs through the tourist complex coincides perfectly with the east - west axis, creating a north - south oriented built front (which is a favorable orientation according to the software Routina Bioclima). However, the high rates of unfavorably oriented roads are due to the streets that stem out vertically to the central axis. This layout works satisfactorily once the secondary entry points to the complex are reduced.

\section{Radial Layout in Lowland Areas, East-West Central Axis}

This part of the study examines and evaluates tourist complexes which are located in lowland areas, facing the waterfront either to the north or south and are designed in a linear arrangement irrespectively of the adjacent coastline.

The results of processing the network of paths of the hotel complex illustrate that the number of paths that are favorably oriented reaches $52.17 \%$ of the total and their corresponding length is $58.91 \%$, in contrast to the number of unfavorably 
oriented which is at $47.83 \%$ and $41.09 \%$ respectively (see.Fig.4).

TABLE IV. RADIAL LAYOUT A NORTH-SOUTH ORIENTATION

\begin{tabular}{|l|c|c|}
\hline & Length & Number \\
\hline Favorable Orientation & $58,91 \%$ & $52,17 \%$ \\
\hline Unfavorable lorientation & $41,09 \%$ & $47,83 \%$ \\
\hline & & \\
\hline
\end{tabular}

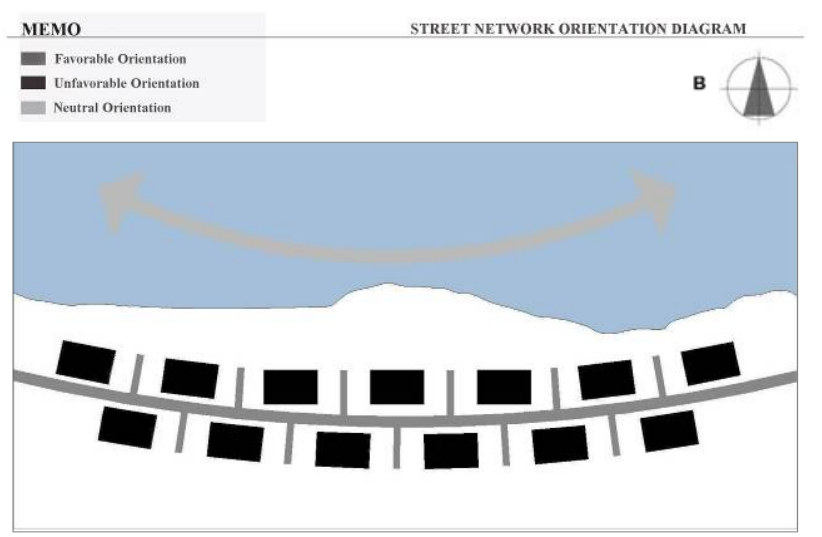

Figure 4. Street Network orientation diagram, as result of Routina Bioclima software, Master plan of settlement

In this case the rates of the favorably oriented roads are greater than those of the unfavorably oriented. The network of roads is developed mainly alongside the sea front, giving favorable orientation and good visual sightlines to all the building units of the complex. Similarly to the case 1.3 , the reduction of secondary entrances (vertical to the main road routes) will significantly reduce the percentage of negativelyoriented street.

\section{E. Rectilinear Layout in Hilly Areas, North-South Central Axis}

The study examines and evaluates tourist complexes that are located in slightly hilly areas, facing the waterfront to the east or west and extending linearly along the contours and coastline.

The result of processing the network of pedestrian streets of the hotel complex illustrate that the number of footpaths that are favorably oriented reach $28.57 \%$ of the total and their corresponding length $29.82 \%$, as opposed to the unfavorably oriented which amount to $71.43 \%$ and their corresponding length $70.18 \%$ respectively (see.Fig.5). It should be noted that the percentages of the negatively oriented routes exceed those of the favorably oriented.

TABLE V. RECTILINEAR LAYOUT ON A N EAST-WEST ORIENTATED HILLY SITES
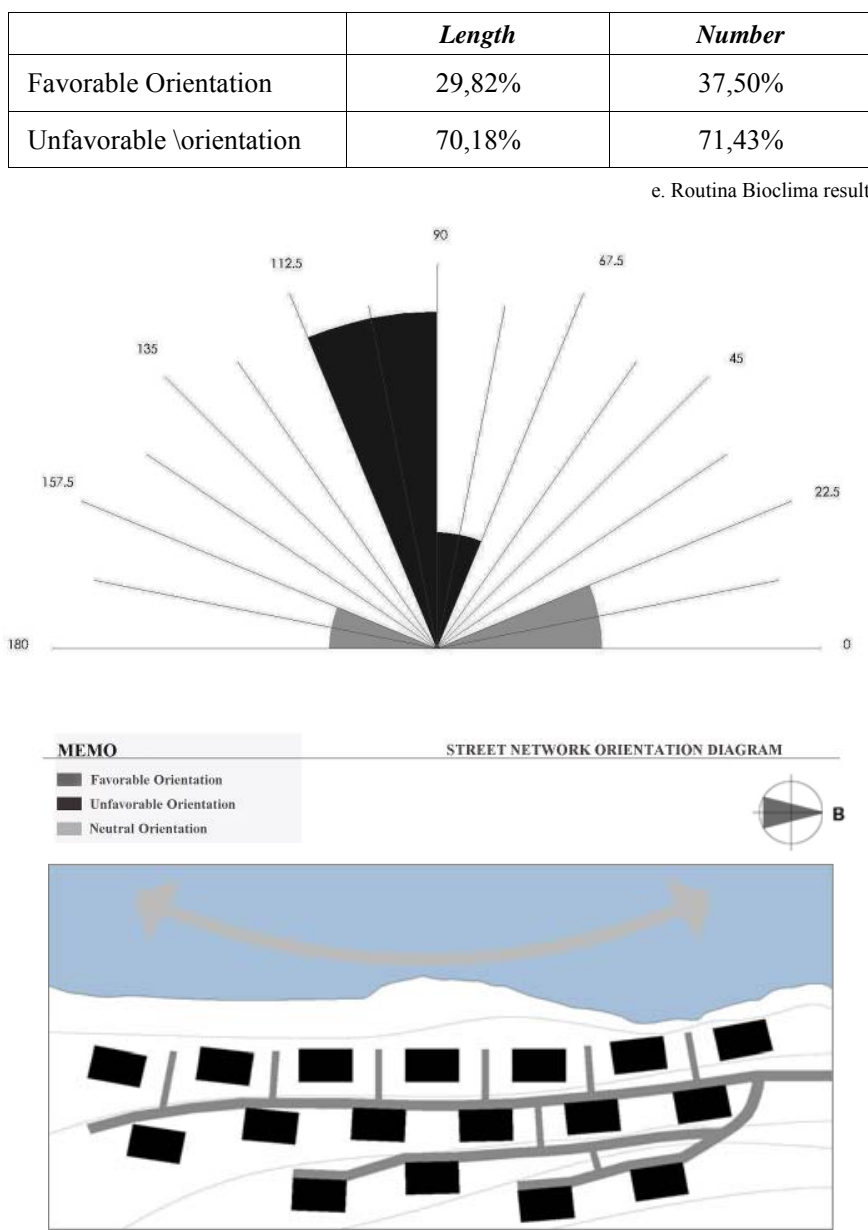

Figure 5. Street Network orientation diagram, as result of Routina Bioclima software, Master plan of settlement

Although the complex has a radial layout following closely the contours of the site and the coastline, the open sightlines towards the horizon are not in the direction of good orientation resulting in the built units having an unfavorable orientation. The favorable orientation coincides with the auxiliary roads that are vertical to the coastline. The proposed layout is not successful.

\section{F. Rectilinear Layout in Hilly Areas, East-West Central Axis}

The study examines and evaluates tourist complexes that are located in slightly hilly areas, facing the waterfront to the north or south and growing linearly along the contours and coastline. 
According to the results of processing the network of pedestrian streets of the hotel complex, the number of footpaths that are favorably oriented reaches $68.00 \%$ of the total and their corresponding length in $66.46 \%$, as opposed to unfavorably oriented, which amounts to $32.00 \%$ and $33.54 \%$ respectively (see.Fig.6). It is clear that the percentage of favorably oriented routes exceeds those of the unfavorably.

TABLE VI. RECTILINEAR LAYOUT ON A NORTH-SOUTH ORIENTATED HILLY SITE

\begin{tabular}{|l|c|c|}
\hline & Length & Number \\
\hline Favorable Orientation & $66,46 \%$ & $68,00 \%$ \\
\hline Unfavorable lorientation & $33,54 \%$ & $32,00 \%$ \\
\hline & & \\
\hline
\end{tabular}

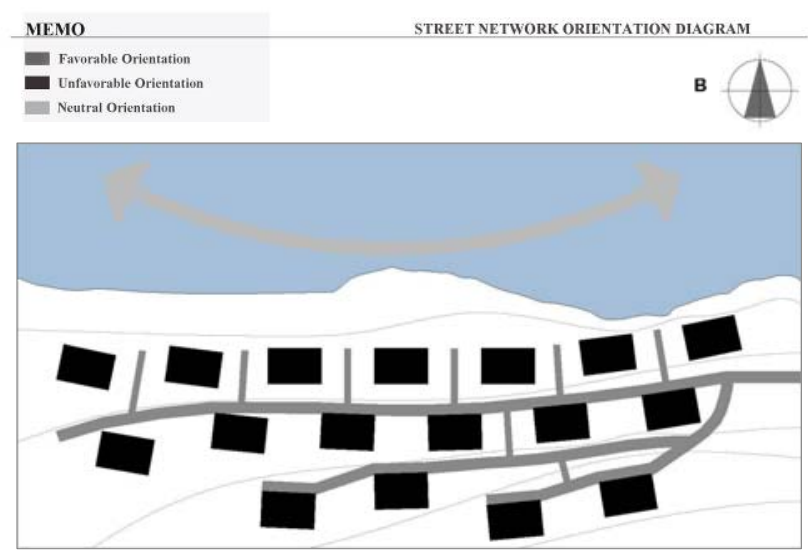

Figure 6. Street Network orientation diagram, as result of Routina Bioclima software, Master plan of settlement

The ratio of unfavorable to favorable orientation is considered to give satisfactory levels of direct solar radiation and natural light inside the tourist complex. It should be noted that this layout would be ideal in the case that the sea front was along the south side of the site (the settlement would be rotated by $180^{\circ}$ ). In this case, all buildings would have the desired favorable orientation, would be developed parallel to the contours without altering drastically the landscape and the terrain, achieving in the same time a good analogy of structured - unstructured space and satisfactory levels of natural ventilation.

\section{G. Order in Peninsula}

The study examines and evaluates tourist complexes that are located in slightly hilly areas or lowland areas, facing the waterfront to the south, east and west and growing linearly along the contours and coastline.

According to the results of the processing the network of pedestrian streets of the hotel complex, the number of footpaths that are favorably oriented reaches $28.57 \%$ of the total and their corresponding length is $29.82 \%$, as opposed to the negatively oriented, which amounts to $71.43 \%$ and $70.18 \%$ respectively (see.Fig.7)

TABLE VII. $\quad$ LAYOUT ON A PENINSULA EXTENDING TO THE SOUTH

\begin{tabular}{|l|l|l|}
\hline & Length & Number \\
\hline Favorable Orientation & $29,82 \%$ & $28,57 \%$ \\
\hline Unfavorable \orientation & $70,18 \%$ & $71,43 \%$ \\
\hline \multicolumn{2}{|r}{ g. Routina Bioclima results }
\end{tabular}

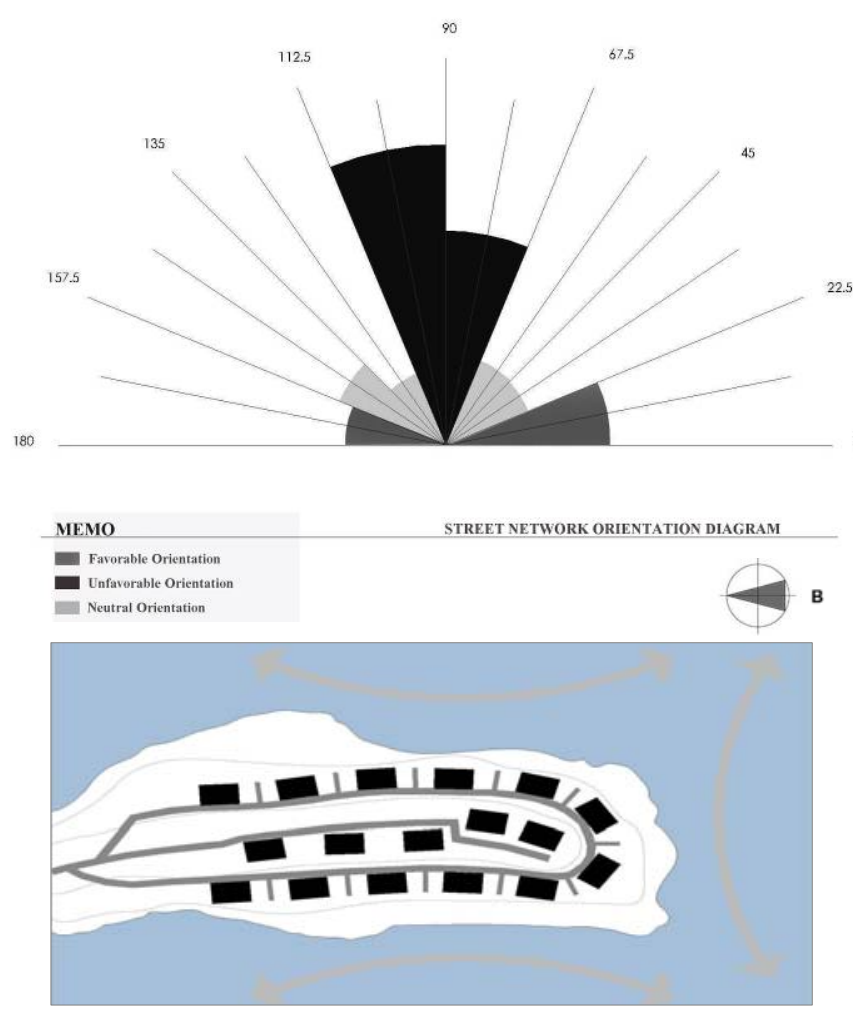

Figure 7. Street Network orientation diagram, as result of Routina Bioclima software, Master plan of settlement

It should be noted that the percentages of negatively oriented channels exceed those of the favorable and neutral orientations. This particularity lies in the fact that the network of footpaths is developed, primarily around the peninsula, alongside the waterfront, does not to follow the lines of the north - south, east - west in an effort to allocate the tourists in different parts the complex. Although the number of negatively 
oriented streets is quite large, especially in the fifth and fourth quartile (Fig. 7), the low rate of building and road width ratiothe open spaces, do not create overlap between the buildings, therefore achieve satisfactory ventilation.

\section{H. Order in Peninsula}

The study examines and evaluates tourist complexes that are located in slightly hilly areas or lowland areas, facing the waterfront to the north, south and east and are growing linearly along the contours and coastline.

According to the results of processing the network of walkways of the complex the number of footpaths that are favorably oriented reaches $71.23 \%$ of the total and their corresponding length is $72.62 \%$, as opposed to the negatively oriented, which amounts to $16.44 \%$ and $15.75 \%$ respectively (see.Fig.8).

It is clear that the percentage of favorably oriented channels significantly exceeds the rates of unfavorable and neutral orientations. This particularity lies in the fact that the network of footpaths is developed, primarily around the peninsula, alongside the sea front, along routes approaching the direction east - west in an effort to allocate the tourists to the different parts of the complex. It should be noted that the relatively high unfavorable orientation is due to the perpendicular to the main road routes. This layout is an ideal solution, based on the location and orientation as it satisfies all the requirements of a holiday complex, offering an ideal orientation that gives plants and microclimate satisfactory thermal comfort, good visual lines towards the sea and the horizon and satisfactory ratio of structured - unstructured space.

TABLE VIII. LAYOUT ON A PENINSULAR EXTENDING TO THE WEST

\begin{tabular}{|l|c|c|}
\hline & Length & Number \\
\hline Favorable Orientation & $72,62 \%$ & $71,23 \%$ \\
\hline Unfavorable \orientation & $15,75 \%$ & $16,44 \%$ \\
\hline
\end{tabular}

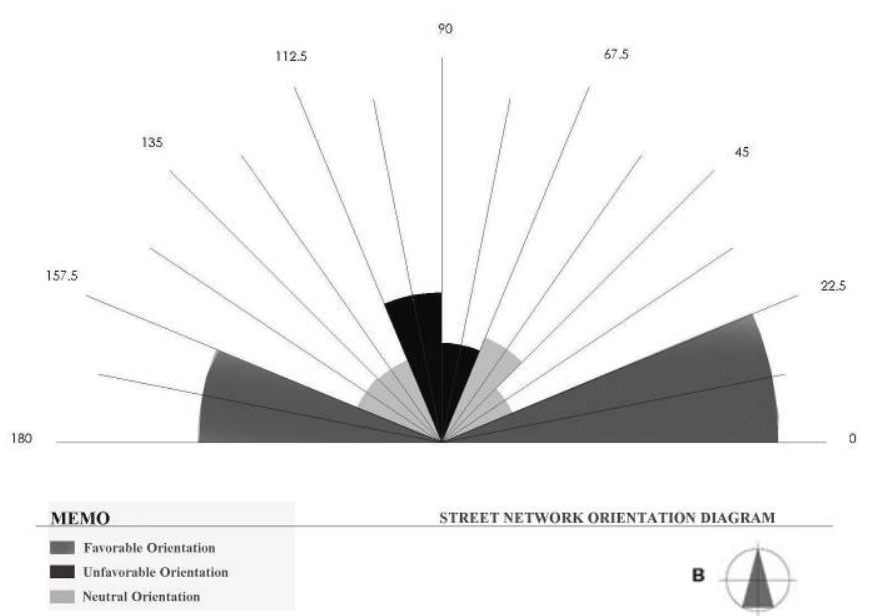

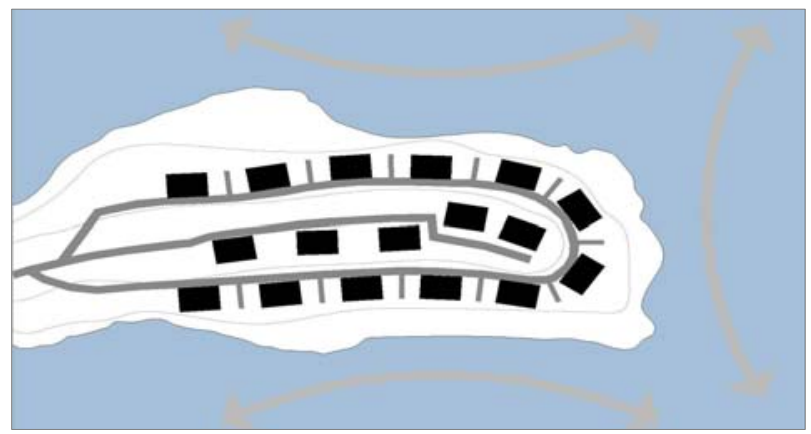

Figure 8. Street Network orientation diagram, as result of Routina Bioclima software, Master plan of settlement

\section{SUPPLEMMENTARY DESIGN PRINCIPLES FOR COASTAL TOURIST SETTLEMENTS}

The second part of the study explores a number of other parameters which consist of useful design principles and which could result in improving the microclimate of the tourist settlement and the bioclimatic behavior of the individual built units, when considered in the early stages of design. In particular, the following parameters have been identified as the most important:

a. The geometry of the layout in relation to the ratio of the width of streets and height of the units. This parameter determines the percentage and adequacy of direct solar radiation received by the individual units as well as the percentage of natural ventilation and cooling within the tourist complex.

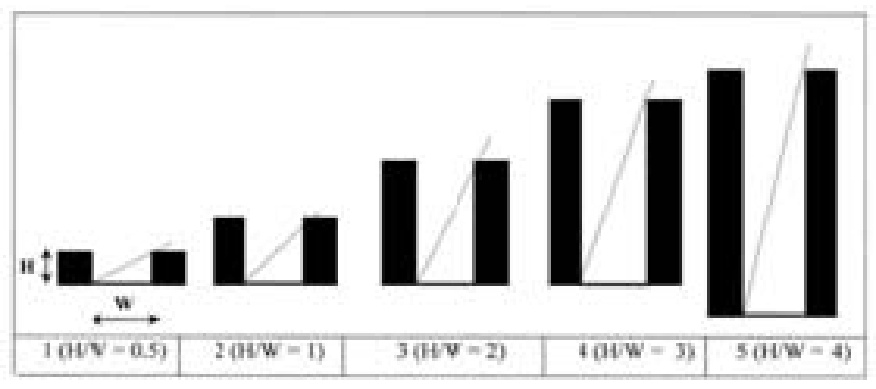

Figure 9. Geometry of urban roads with different proportions of buildings heights to width of roads $(\mathrm{H} / \mathrm{W})$ for an East - West Orientation.

Better air infiltration within the tourist complex could be achieved by providing for satisfactory distances between buildings.

b. The final spatial configuration. A layout of units that consists of vertical to the sea-front indirect routes provides circulation channels for upward air currents during the day and downward air currents at night between the sea and the tourist complex. 

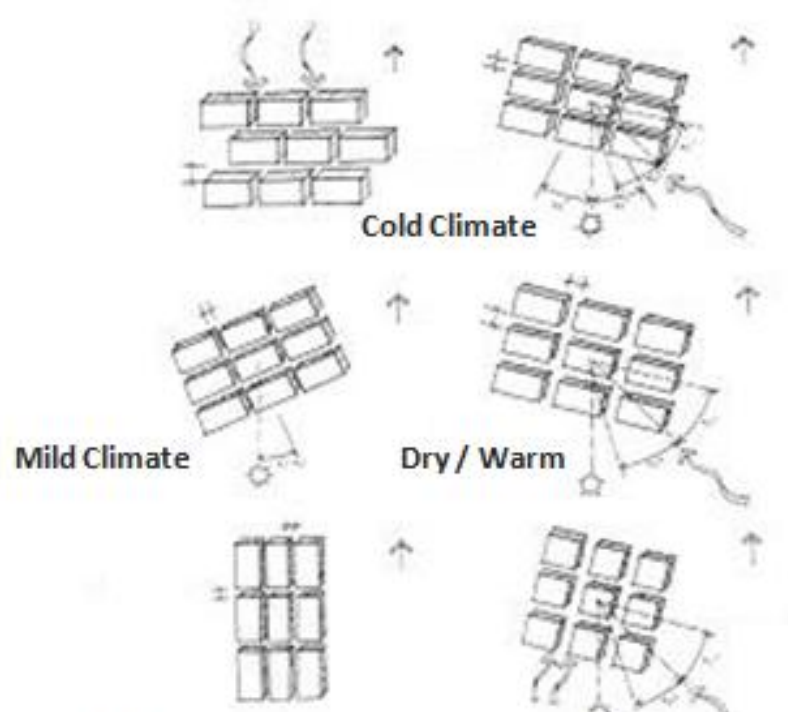

Tropical / Dry

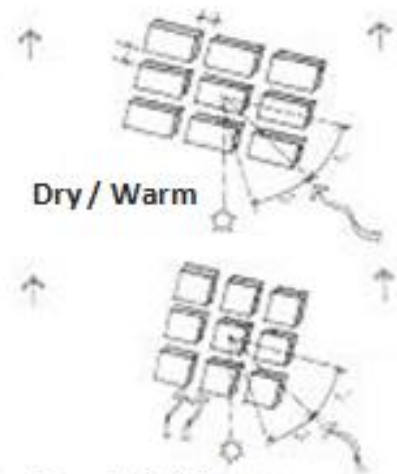

Tropical / Humid

Figure 10. Recommended way of planning buildings, based on climate.

This air flow could be exploited, firstly for lowering the temperatures of the microclimate through carefully designing the outdoor spaces of the tourist complex with the correct juxtaposition of volumes on the site and choice of an interwoven layout, and secondly for cooling the building units through the correct choice of the location, proportion and shape of the openings formed on each of their main facades.

c. The design of the size of the openings of a building unit are the most efficient and cost-effective factor in determining the role of the building as a solar collector. The south oriented surfaces receive more solar radiation in winter than in summer which works in agreement with the heating requirements of the buildings. The means to achieve this basic design principle is to design the south facade with openings covering approximately $60 \%$ of the total area, to provide for mediumsized openings in the eastern and western side (to avoid overheating during the summer months), and despite the fact that North openings offer good quality diffused lighting, and do not receive direct sunlight, to have openings on the north side with limited surface, to avoid large heat losses during the winter months.

It is thus preferable to have openings on the south and north facade, to reinforce the natural air infiltration. In parallel, it is the necessary to provide sufficient sun protection to avoid overheating and achieve minimal incoming radiation in summer, without restricting the natural lighting of the units, good ventilation and viewing through the shading of openings by fixed or mobile shading devices.

d. The landscape design. The intensity of the air can be managed through the careful choice of planting i.e. the use of conifers instead of deciduous trees, etc.

It should be noted that all the previously mentioned principles determine the sustainability of coastal developments in the cases of both touristic and residential settlements.

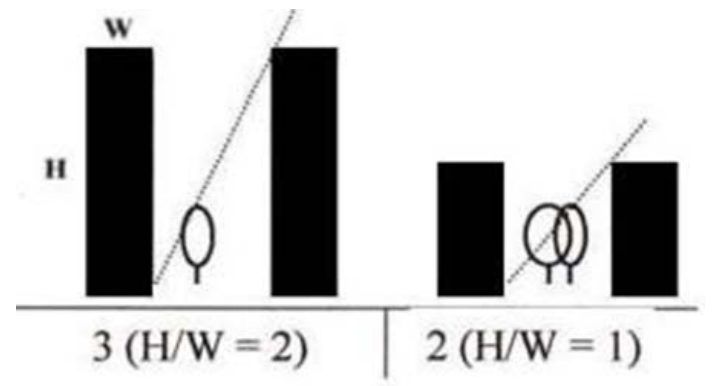

Figure 11. Recommended Ratio of Heightn to Width using vegetation

\section{CONCLUSIONS}

The microclimate of coastal tourist settlements is the primary factor that should be taken into account in their design. High levels of salinity should inform design decisions such as the choice of materials, whereas wind dynamics, higher temperatures and hunidity levels dictate the need to achieve sustainability through the optimum orientation of the buildings on site, the correct ammount of voids and solids in the settlements's built fabric as well as the ideal ratio of openings on each of the buildings' facades depending on their orientation.

The software Routina Bioclima by considering the particular characteristics of these areas analyzes the roads of each configuration recognizing the number and orientation of roads, codifying them into groups according to their position in relation to either the North-South axis (favorable orientation) or the East-West axis (unfavorable orientation). It can be applied as a tool to evaluate tourist settlements which are already built but more importantly, as a means to inform design decisions at the early stages of strategic master planning, particularly in the case of large scale coastal sites where the designer is offered the possibility to choose between different configurations within the confines of the same site. Finally, it can also be used by developers as a tool of selecting the appropriate site in the cases where sustainability is a project priority.

In this study, taking into account specific climatic characteristics through the application of the simulation processes of Routina Bioclima, we evaluated some of the most common configurations of tourist complexes, as far as the levels of natural daylight and ventilation inside the individual building units, which comprise them, are concerned. The process was intented to be indicative as far as the results of Routina Bioclima are concerned but also serve as a way to highlight the design principles that lie behind the design of coastal tourist settlements. The two main results of the research were:

1) In the case where the complexes have a central circulation axis, it is preferable for sustainability reasons that this axis coincides with the axis of the East - West or diverge from it a maximum angle of $30^{\circ}$, creating building fronts that have a North and South orientation. The distance between buildings should be sufficient to achieve the right proportion of built and free spaces for the purpose of good natural ventilation, and unobstructed views towards the horizon. The same design 
principles apply in the case of linear configurations on a sloping site with the provision that the different building units are adjusted to the contours of the site.

2) In the case of configurations of touristic complexes on a peninsula, the arrangement of the units around the perimeter is successful, as far as the levels of daylight and ventilation are concerned, provided that the main circulation axis is parallel to the direction of East - West, creating North and South facing building fronts, and that the perpendicular to the main road, auxiliary streets are eliminated.

TABLE IX - SUMMARIZING THE RESULTS OF ROUTINA BIOCLIMA FOR THE PARADIGMES APPLIED FOR THE PURPOSES OF THIS STUDY.

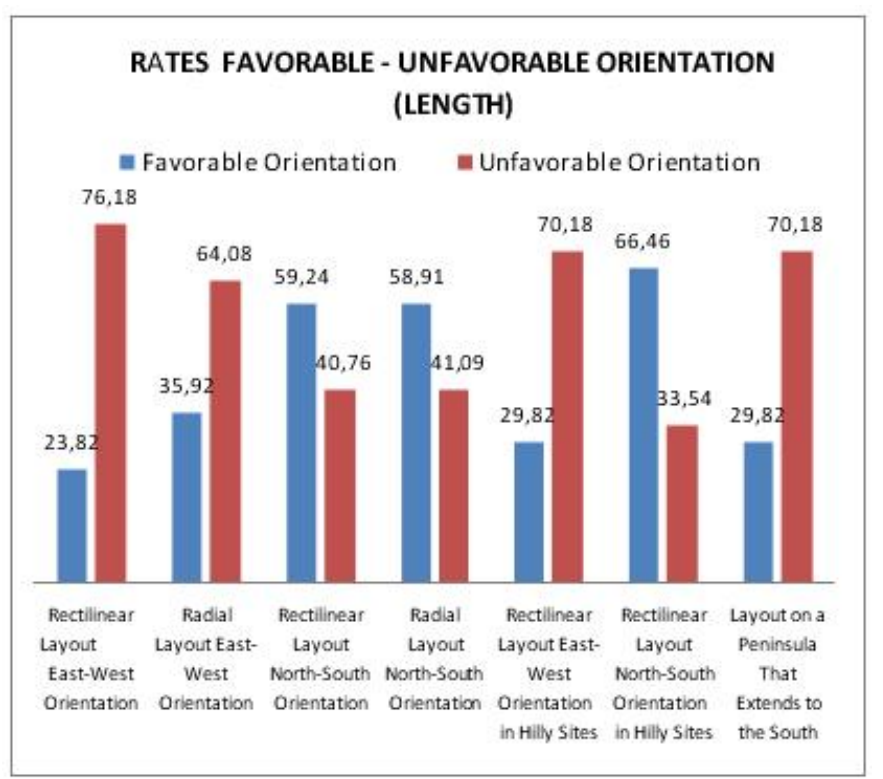

To conclude, it should be noted that except from the climatic phenomena that are related to large bodies of water, coastal areas have varied and very particular local climatic characteristics. The proposed research process is intended to serve as a first reading of the site, investigating the relationship between the proposed building units of the tourist complex, the orientation, the particular geographic relief of a site and the waterfront. In the cases, where the proposed tourist complex does not fully coincide with one of the studied configurations the designer should take into account and insert into the software Routina Bioclima more parameters such as the latitude and longitude of a particular location, the wind direction and intensity, the local rainfall data, and the geological characteristics.

\section{ACKNOWLEDGMENT}

We would like to thank D. Rigopoulos for creating the software ROUTINA BIOCLIMA, which was used in this study.

\section{REFERENCES}

[1] Buckingham - Hatfield, S. and B. Evans (Eds). (1996). Environmental Planning and sustainbility. John Wiley \& Sons Lid, Chichester, UK.

[2] Fazia, Ali-Toudert, 'Dependence of outdoor thermal comfort on street design in hot and dry climate', Freiburg, Dissertation Berichte des Meteorologischen Institutes der Universität Freiburg, Nr. 15, ISSN 1435-618X, 2005.

[3] Georgi N.J., Sarikou S., 'The usage of Nature friendly materials in Urban Public Spaces', Jour.WSEAS Transaction, Vol.1(2), ISSN 1790 5079, pp. 173-1862-4, Nov. 2005.

[4] Haaren C. and Reich M., 'The German way to greenways and habitat networks', Landscape and Urban Planning (in press), 2004.

[5] Heisler, G.M, 'Mean wind speed below building height in residential nneighbourhoods with different tree density', ASHRAE. Translation, vol. 96, pp 1389-1396, 1990

[6] Kaplan, R., Kaplan, S., Ryan, R., 'With people in mind: Design and management of everyday nature', Washington, Island Press, 1998.

[7] METEONORM, Global Meteorological Database for Solar Energy and Applied Climatology, Swiss Federal Institute of Technology, Zurich, Switzerland.

[8] Pieri S.P., Pieris P., K. Sfakianaki, K. Vasilakopoulou, M. Santamouris, Prototype Zero Energy Tourist Settlement", 2010, PALENC, International Conference.

[9] Pieri S.P., M. Xenakis, I. Tzouvadakis, Tourism and the Environment / Strategies of Sustainable Tourism Development 4rth National Conference for the Implementation of Renewable Energy Sources, Athens 2010.

[10] Ruff A., Tregay R., 'An ecological approach to Urban Landscape Design', University of Manchester: Department of Town and \& Country planning, Occasional paper no 8, 1982.

[11] Sarikou S., 'Encouraging Nature in Urban Public parks: An evaluation of the results of the ecological approach of 70s, in UK's Urban Nature Parks', WSEAS, IASME Transactions, Vol.2(4), ISSN 1790-031X, p.p. 512-518, June 2005.

[12] Southworth M., 'Designing the walkable city', Journal of Urban Planning and Development, DOI: 1061/ASCE 0733-9488, Vol.4(246) pp131., 2005.

[13] United Nations Division for Sustainable Development(1999) Sustainable development success stories. New York 